Pain, opioids, and the competence to consent. \$4924

7. Jerome Fan MD. Division of Emergency Medicine, McMaster University, Hamilton, Ont.

A prospective validation of the Triage Risk Screening
Tool for elders in a Canadian emergency department. $\$ 3200$

Correspondence to: Dr. Eric Grafstein; egrafstein@providencehealth .bc.ca

\title{
Introducing a new Web site for aspiring EM physicians
}

$\mathrm{M}$ edical students considering a career in emergency medicine have a new resource. Information, career tips and links of interest to medical students are available in one location on the new CAEP student site:

\section{www.caep.ca/006.residents/006-05.students.htm}

Designed for medical students, by medical students, this site has many useful features, including:

- opportunity to view CAEP conference presentations
- EM insight from specialists in the field

- tips and advice for applying to residency programs

- links to journal articles relevant to students considering EM

The site is a dynamic and current source for information targeted to students considering an EM career. We are always looking for new content, including personal insight, tips regarding a career in EM, Internet sites of interest, anecdotes. The site is updated regularly, so please email comments to medstudents@ caep.ca

\section{In memory of Dr. Peter Lane}

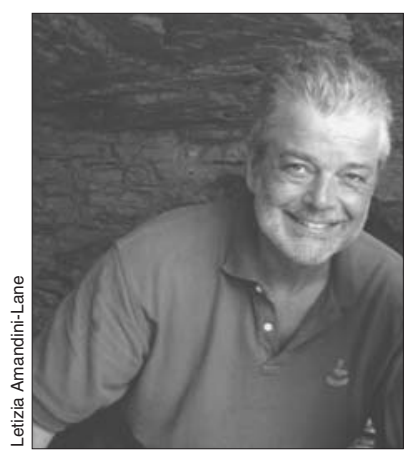

CAEP would like to express sincere appreciation for a gift of $\$ 1000$ in memory of former CAEP President Peter L. Lane, MD, FRCPC, who died tragically on August 27, 2003. The gift was provided by Peter's parents, Mr. and Mrs. R.L. Lane, of Ottawa.

"We were touched by CAEP's provision of $\$ 1000$ to honour Peter's memory and we decided to match it," said Mr. Lane. "CAEP was close to Peter's heart. We want to help keep his memory alive by supporting what he was most interested in - emergency medicine research."

The total amount of $\$ 2000$ has been donated to the CAEP Research Endowment Fund, which was established by CAEP to support Canadian emergency medicine research and to develop junior investigators. 